\title{
Root Dentine Strain Generation during Root Canal Instrumentation with Rotation and Reciprocation Motions
}

\author{
Bnar O. Hamafaraj ${ }^{1 *}$, Raed F. Salman² \\ ${ }^{1}$ Department of Conservative, College of Dentistry, Tishk International University, Erbil, Kurdistan Region, Iraq, ${ }^{2}$ Department of Conservative, \\ College of Dentistry, Hawler Medical University, Erbil, Kurdistan Region, Iraq
}

\section{${ }^{*}$ Corresponding author: \\ Bnar O. Hamafaraj, \\ Department of Conservative, College of Dentistry, Tishk International University, Erbil, Kurdistan Region, Iraq. E-mail: bnar_jaff@yahoo. com}

Received: 11 March 2020

Accepted: 31 May 2020

Published: 30 December 2020

DOI

10.25156/ptj.v10n2y2020.pp66-70

\section{A B S T R A C T}

The aim of the study is to measure and compare strain generated on root dentine surface by two different instrumentation motions. Thirty extracted single canal premolars were used in this study which randomly was divided into two groups, one group was prepared with ProTaper NEXT X2 file in rotation motion, and the second group was prepared by WaveOne GOLD primary file in reciprocation motion, the canals were irrigated during canal preparation by $2 \mathrm{ml}$ of sodium hypochlorite and $17 \%$ EDTA gel was used. Strain measurement was performed by strain gauges and a digital strain output reader, data were recorded every $5 \mathrm{~s}$ for $50 \mathrm{~s}$. The results of this study have shown that WaveOne GOLD had higher mean $0.7308 \pm 0.41106$ than ProTaper next $0.5385 \pm 0.39904$ which means WaveOne GOLD generates greater strain than ProTaper NEXT. However, according to Student's $t$-test between two groups there is no statistical difference between them. Based on the results of this study, there was no difference between the two motions; both motions generated strain on root dentine surface.

Keywords: Endodontics; Instrumentation; Reciprocation motion; Root canal; Root dentine strain; Rotation motion

\section{INTRODUCTION}

The primary goal of endodontic treatment is to conserve the remaining tooth after dental caries or trauma to assure the retained tooth structure and the following restoration are both functional and esthetic. Success of root canal shaping is the key point for success of endodontic therapy and the following restorations, (Liu and Wu, 2016).

During the previous decades a very rapid and broad development has been made in dentistry (Modh et al., 2018). The first steps toward the development of endodontic are the introduction of nickel-titanium (NiTi) alloy and the subsequent automation of mechanical preparation, (Gavini et al., 2018). Advantage of nickel titanium is its reduced procedural errors such as zipping, stripping ledge formation, and perforations. They are more flexible than stainless steel files which were inflexible with larger file sizes and lead to procedural errors and decreasing the success rate of endodontic treatments. Further advancements in endodontics are single file rotary files which make it able to prepare the root canal system by only one file which has working time less than sequenced rotary systems. In addition to rotary movement, reciprocating movement was introduced into dentistry which is claimed to relieve stress on instrument by its counter clockwise and clockwise motion which disengages the instrument from dentinal wall, (Machado et al., 2010, Khawaja et al., 2016).

During root canal instrumentation, dentinal microcracks may occur apically and extend to the coronal parts of the tooth which may end up in vertical fracture and lead to extraction of the tooth since there is no predictable treatment for vertical root fracture. This problem might occur during canal shaping since during shaping of canals, dentinal walls thickness may decrease and produce stress and strain on root especially in the apical third region in which crack might be easily formed. In addition, strain is also generated on the root dentin surface at the same time with heat production since temperature elevation produces an initial dentinal contraction, followed by its expansion, (Amade et al., 2013; Jamleh et al., 2016). Furthermore, one of the causes that generate microcracks in root dentin was revealed to be the force applied to the root canal walls during mechanical instrumentation of root canal using nickel titanium rotary or reciprocation systems. In addition, tip design, cross-sectional geometry, type of taper, shape of flute, and pitch might also be linked to dentinal crack formation, (Dixit et al., 2016; Carlesi et al., 2018). 
Since there is lack of studies in literature examining strain generation comparing rotation and reciprocation motion. The aim of this study is to evaluate the strain generation by the two motions on external root dentine surface. The null hypothesis tested was that there is no difference among the strain generation for rotation and reciprocation motion.

\section{MATERIALS AND METHODS}

Thirty extracted single canal human premolar teeth whose roots were similar in size and shape were used in this study. Root surfaces of these samples were washed with water to remove blood, soft-tissue remnants and ultrasonic scalers were used to remove calculus form the root surfaces.

To provide a straight line access and to provide a reference point (Jamleh et al., 2015), each sample root was measured to $12 \mathrm{~mm}$ by a digital caliper (TRUPER) and was cut by a diamond disc bur by a slow speed handpiece Figure 1, and was stored in distilled water at room temperature.

The samples were randomly divided into two groups 15 teeth in each based on the endodontic file and the instrumentation motion during root canal. The groups were as following;

- Group 1: ProTaper NEXT file no.: X2(025/06) (PTN; Dentsply Maillefer, Ballaigues, Switzerland)

- Group 2: WaveOne GOLD file no.: Primary (25/07) (WOG; Dentsply Maillefer, Ballaigues, Switzerland).

\section{Tooth Mounting}

Apical third of the teeth were imbedded into $8 \mathrm{~mm}$ length and $10 \mathrm{~mm}$ width self-cure acrylic resin, it was taken into consideration that each tooth sample was placed in the center with long axis of the tooth being perpendicular. During mounting imbedding the teeth, it was made sure to leave middle third of each sample was free for strain gauge attachment.

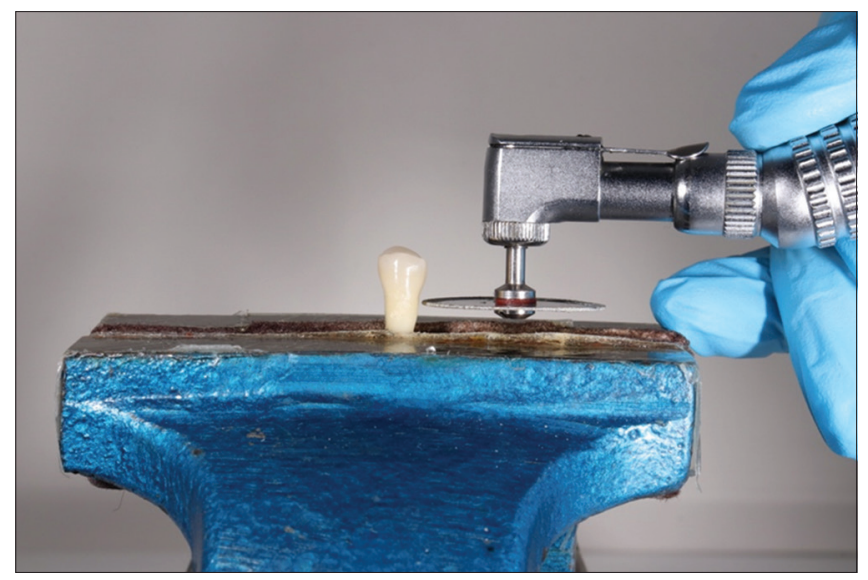

Figure 1: Decoronation process

\section{Strain Measurement}

After cleaning and mounting of the teeth, each sample was acid etched with 37\% phosphoric acid (TehnoDent, Russia) for $15 \mathrm{~s}$ and was washed vigorously with water and was dried with air spray to increase the bonding retention of the strain gauge, (Amade et al., 2013). Epoxy based bonding material (Alteco 3-tone epoxy adhesive, Japan) was mixed in one to one ratio according to manufacturer's instructions; the gauge (BF350-3AA, China) was held by a tweezer at its terminals and a layer of the epoxy-based adhesive was applied to the bottom layer of the strain gauge by its applicator and a layer was also placed on the tooth surface. The samples were left undisturbed for complete setting for $24 \mathrm{~h}$. A thin layer of silicon impression material (Variotime, Kulzer) was placed in the surface of the strain gauge to protect it from the solvents used for irrigation during instrumentation procedure Figure 2, (Amade et al., 2013).

Strain gauges were connected to strain gauge amplifier load cell (SMOWO, China) through two electric clamps and the load cell amplifier was connected to digital strain output reader (OMEGA DP25B, USA), Figure 3 During root canal instrumentation strain was recorded by this system at $5 \mathrm{~s}$ intervals for $50 \mathrm{~s}$ which was a mean time for canal preparation.

\section{Root Canal Preparation and Irrigation}

Working length and canal patency were previously established for each sample by introducing size $10 \mathrm{~K}$-file into the canal until the tip of the file was just visible at the end of the canal before mounting the sample to acrylic base the and the working lengths were set by $1 \mathrm{~mm}$ shorter from the apex. Canal patency was established by a size 10 $\mathrm{K}$-file in watch winding motion, along with irrigation with $5.25 \%$ sodium hypochlorite.

After confirmation of the glide path, the samples were mounted on vise and the canal instrumentation procedure

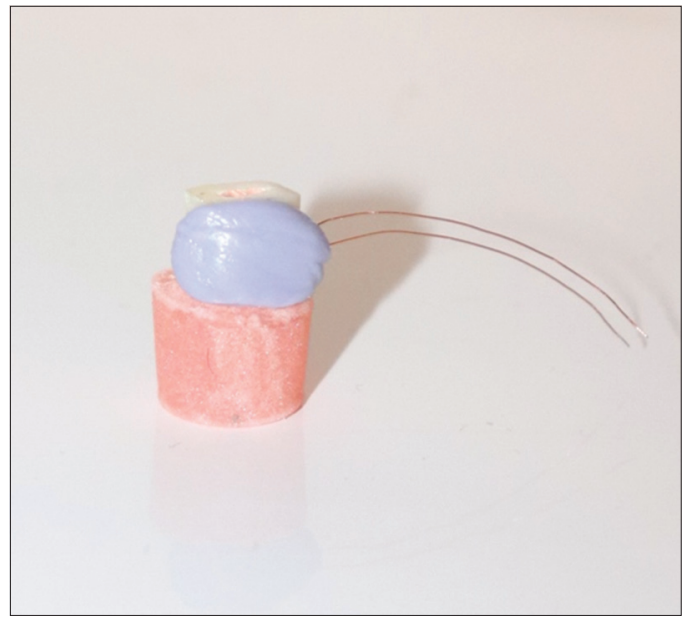

Figure 2: Strain gauge is covered by silicone impression material 
for the first group was started with ProTaper NEXT $\mathrm{X} 2(25 / 06)$, the canals were instrumented in brushing motion with concomitant irrigation with $2 \mathrm{ml} 5.25 \%$ sodium hypochlorite irrigation solution according to the pilot study done previously with determined number of strokes and duration for full instrumentation, later, the files were cleaned with a cotton roll to remove dentinal debris during the root canal preparation process. This procedure was followed by $1 \mathrm{ml}$ of $17 \%$ EDTA gel for $1 \mathrm{~min}$ and then flushed by $10 \mathrm{ml}$ of $5.25 \%$ sodium hypochlorite and finally followed by a flush of $10 \mathrm{ml}$ of saline and the irrigation needle was placed inside the canal to the $3 \mathrm{~mm}$ shorter from the full working length, (Amade et al., 2013). To standardize the technique, the canals were prepared with a total of 12 strokes to the full working length which was enough for complete canal preparation according to the previously done pilot study. The second group was prepared in reciprocation motion with WaveOne GOLD (Dentsply Maillefer, Ballaigues, Switzerland) and the X smart plus endodontic motor was set up on WaveOne GOLD pre-programmed option that is present in the device. The canals were instrumented, in the same manner was previously mentioned.

In both groups, each sample was prepared 1 for $50 \mathrm{~s}$ which was the average time for preparation of the canal. In addition, each file was used for only two samples and was discarded.

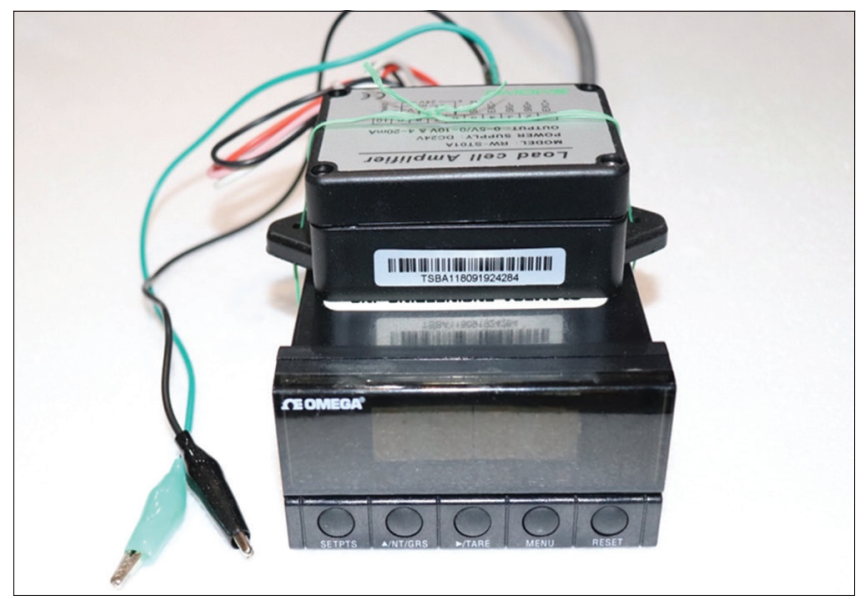

Figure 3: Connection of electric clamp, amplifier, and digital output reader
The recorded data were then statistically analyzed by descriptive statistics and $t$-test for difference between two groups of motions (rotation and reciprocation).

\section{RESULTS}

The mean of strain elevation and standard deviations for the experimental groups are shown in Table 1. Descriptive statistic between two groups, ProTaper NEXT for rotary motion, and WaveOne GOLD for reciprocation motion, have shown that WaveOne GOLD had higher mean $0.7308 \pm 0.41106$ than ProTaper next 0.5385 \pm 0.39904 which means WaveOne GOLD generates greater strain than ProTaper NEXT Tables 1 and 2.

Student's $t$-test have shown that there is no significant difference $(P>0.05, P=0.352)$ between the WaveOne Gold (reciprocation) and ProTaper Next(rotation) in strain generation on root dentine Table 3.

\section{DISCUSSION}

In this in vitro study, the strain generation on root dentine surface during root canal preparation with two different instrumentation motions was investigated. The results of this study supported the null hypothesis that there is no difference between the strain measurements of rotation and reciprocation motion. There was no statistical difference between the ProTaper NEXT and WaveOne GOLD files in strain generation during root canal preparation.

Canal shaping is a critical stage for successful treatment of the root canal as it provides sufficient room for effective disinfection and root canal filling. However, this procedure may weaken root dentine structure, since during root canal preparation dentinal thickness decreases which leads to strain accumulation, (Hulsmann et al., 2005; Jamleh et al., 2016). In addition, intra canal rotation of the file inside the root canal can increase the strain leading to root deformation such as micro cracks, (Miguéns-Vila et al., 2017). Cassimiro et al., 2017, have stated that root canal morphology, in addition to cross section of the instrument would affect the amount of contact with the root dentine which, in turn, may increase tension in addition they also

Table 1: Mean maximum strain (in $\mu S$ and \pm Standrad deviation) defined by descriptive statistics ( $n=15$ ) as strain generation during root canal instrumentation showing that WaveOne GOLD had higher strain generation than ProTaper NEXT

\begin{tabular}{|c|c|c|c|c|c|c|c|}
\hline \multicolumn{8}{|c|}{ Descriptive statistics } \\
\hline \multirow{2}{*}{$\begin{array}{l}\text { Descriptive } \\
\text { Statistics Between } \\
\text { PTN and WOG }\end{array}$} & \multirow{2}{*}{$\frac{n}{\text { Statistic }}$} & \multirow{2}{*}{$\begin{array}{l}\text { Minimum } \\
\text { Statistic }\end{array}$} & \multirow{2}{*}{$\frac{\text { Maximum7 }}{\text { Statistic }}$} & \multicolumn{2}{|c|}{ Mean } & \multirow{2}{*}{$\frac{\text { SD }}{\text { Statistic }}$} & \multirow{2}{*}{$\begin{array}{l}\text { Variance } \\
\text { Statistic }\end{array}$} \\
\hline & & & & Statistic & SE & & \\
\hline PTN & 15 & 0.10 & 1.30 & 0.5385 & 0.11067 & 0.39904 & 0.159 \\
\hline WOG & 15 & 0.20 & 1.50 & 0.7308 & 0.11401 & 0.41106 & 0.169 \\
\hline
\end{tabular}

SD: Standard deviation, SE: Standard error, PTN: Pro taper NEXT, WOG: Wave one GOLD 
Table 2: $P$ value of mean strain between reciprocation and rotary motions showing that there is no significant difference between the experimental groups

\begin{tabular}{|c|c|c|c|c|c|c|c|c|}
\hline \multicolumn{9}{|c|}{$t$-test } \\
\hline \multirow{3}{*}{$\begin{array}{l}\text { t- Test } \\
\text { Between PTN } \\
\text { and WOG }\end{array}$} & \multicolumn{5}{|c|}{ Paired differences } & \multirow[t]{3}{*}{$t$} & \multirow[t]{3}{*}{ df } & \multirow[t]{3}{*}{ Significant. (two-tailed) } \\
\hline & \multirow[t]{2}{*}{ Mean } & \multirow[t]{2}{*}{ SD } & \multirow{2}{*}{ SEM } & \multicolumn{2}{|c|}{$95 \% \mathrm{Cl}$ of the difference } & & & \\
\hline & & & & Lower & Upper & & & \\
\hline PTN - WOG & -0.19231 & 0.71585 & 0.19854 & -0.62489 & 0.24027 & -0.969 & 28 & 0.352 \\
\hline
\end{tabular}

SD: Standard deviation, SEM: Standard error of mean, Cl: Confidence interval, PTN: Pro taper NEXT, WOG: Wave one GOLD

Table 3: Bar chart showing strain difference between the two motions

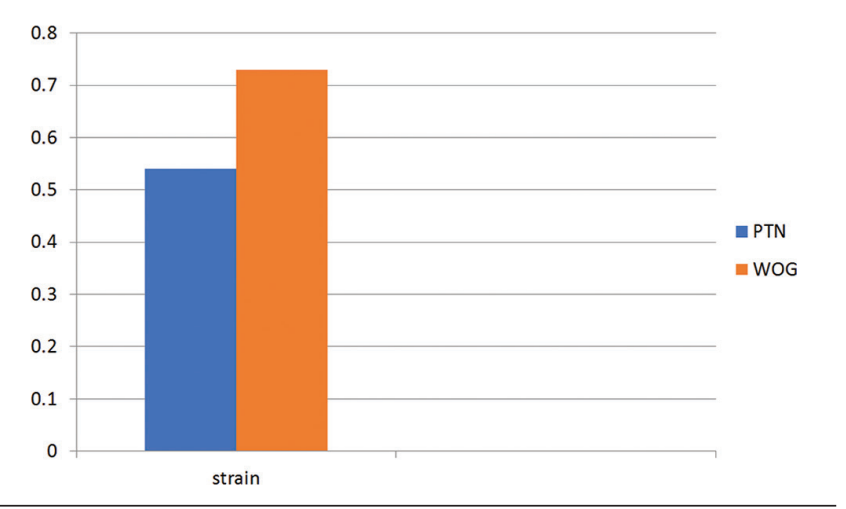

mentioned in their study, tip design of rotary instrument, the taper type could also be related with dentinal microcrack formation, (Cassimiro et al., 2017).

Pro'Taper NEXT s a fifth-generation file that has an offset of mass of rotation with two cutting edges, which produce a mechanical wave motion that moves along the file length which, in turn, minimizes the engagement between the file and dentin in addition, this offset design provides a better cross-sectional space that improves cutting, loading, and debris removal out of canal when compared with a centered mass of rotation file, (Ruddle et al., 2013). On the other hand, WaveOne GOLD file has an alternating offset parallelogram cross-section design which limits the contact with the dentin to one or two points thus reducing taper lock and the screw effect, (Ruddle, 2016). These characteristics of the file designs can be the reason why there were no significant differences in the obtained results of this study.

Furthermore, in this study Pro'Taper next X2(25,06) file and WaveOne GOLD (primary 25,07) files were used in canal preparation, although same size of file was used but their taper is different, this different might be the reason of the higher mean of the WaveOne Gold file in strain generation. Cassimiro et al. in their study compared the effects of different instruments which included ProTaper NEXT and WaveOne GOLD instruments on root canal wall, in their result they found that there was no statistical difference between the groups; all the groups have shown degree of microcracks. Furthermore, Burklein et al., when comparing rotation motion and reciprocation motion, found that dentinal microcracks were present in all the prepared canals and there was no statistical difference between the reciprocation and the rotation groups, (Cassimiro et al., 2017, Bürklein et al., 2013) which supports the results of our study.

In this study, strain gauges have been used to evaluate the amount of strain generated by the two different reciprocation motions. Strain gauges is the most commonly used method of strain measurement due to its accessibility and ease of use and application on tooth surface however a special attention should be given to protect the gauges from irrigants since Amade et al. have reported that irrigants effect the readings of the gauges.

To different anatomical variations, single rooted premolars were used in this study. Extra oral environment, tooth storage media, and post-extraction dentinal changes might all effect the results as they are completely different from intraoral environment, a completely different data can be obtained in an intraoral environment. Thus, further studies should be done for reciprocation motion and rotation motion assessment.

\section{CONCLUSION}

Within the limitation of this study, both rotation and reciprocation motion generated strain on root dentine surface and there was no significant difference in strain generation between the two motions. However, the strain generated by rotation motion was found to be less than reciprocation motion.

\section{ACKNOWLEDGMENTS}

The authors would like to thank Tamer Levant Company for providing X-smart plus Endomotor and Dr. Mohammed Husam his great help in strain measuring device connections.

\section{REFERENCES}

Amade, E. S., V. R. Novais, M. G. Roscoe, F. M. F. Azevedo, A. A. Bicalho and C. J. Soares. 2013. Root dentin strain and temperature rise during endodontic treatment and post 
rehabilitation. Braz. Dent. J. 24: 591-598.

Bürklein, S., P. Tsotsis and E. Schäfer. 2013. Incidence of dentinal defects after root canal preparation: Reciprocating versus rotary instrumentation. J. Endod. 39(4): 501-504.

Carlesi, T., G. Nigro, L. D. Giacomo, G. Plotino and V. A. Malagnino. 2018. Dentinal microcrack formation during root canal treatment with Mtwo instruments and microseal filling technique. J. Adv. Oral Res. 9(1-2): 31-37.

Cassimiro, M., K. Romeiro, L. Gominho, A. de Almeida, L. Costa and D. Albuquerque. 2017. Occurence of dentinal defects after root canal preparation with R-phase, $\mathrm{M}$-wire and gold wire instruments: A micro-CT analysis. BMC Oral Health. 17(1): 93.

Dixit, H., M. Nair, N. Shah and V. Pandit. 2016. Incidence of dentinal crack formation during various endodontic procedures. Int. J. Oral Health Med. Res. 2(6): 125-128.

Gavini, G., M. dos Santos, C. L. Caldeira, M. E. L. Machado, L. G. Freire, E. F. Iglecias, O. A. Peters and G. T. M. Candeiro. 2018. Nickel-titanium instruments in endodontics: A concise review of the state of the art. Braz. Oral Res. 32: e67.

Hulsmann, M., O. A. Peters and P. M. H. Dummer. 2005. Mechanical preparation of root canals: Shaping goals, techniques and means. Endod. Top. 10(1): 30-76.

Jamleh, A., C. G. Adorno, A. Ebihara and H. Suda. 2016. Effect of nickel titanium file design on the root surface strain and apical microcracks. Aust. Endod. J. 42(1): 25-31.

Jamleh, A., T. Komabayashi, A. Ebihara, M. Nassar, S. Watanabe, T. Yoshioka, K. Miyara and H. Suda. 2015. Root surface strain during canal shaping and its influence on apical microcrack development: A preliminary investigation. Int. Endod. J. 48(12): 1103-1111.

Khawaja, N., R. Lal, M. Rehman and S. K. Punjabi. 2016. Endodontics procedural errors. Prof. Med. J. 23(12): 1537-1540.

Liu, W. and B. Wu. 2016. Root canal surface strain and canal center transportation induced by 3 different nickel-titanium rotary instrument systems. J. Endod. 42(2): 299-303.

Machado, M. E. L., L. A. B. Sapia, S. Cai, G. H. R. Martins and C. K. Nabeshima. 2010. Comparison of two rotary systems in root canal preparation regarding disinfection. J. Endod. 36(7): 1238-1240.

Miguéns-Vila, R., B. Martín-Biedma, P. Varela-Patiño, M. Ruíz-Piñón and P. Castelo-Baz. 2017. Vertical root fracture initiation in curved roots after root canal preparation: A dentinal micro-crack analysis with LED transillumination. J. Clin. Exp. Dent. 9(10): e1218.

Modh, H., V. Sequeira, A. Belur, N. Arun, S. Dhas and G. Fernandes. 2018. Newer trends in endodontic treatment: A review. J. Dent. Med. Sci. 17(1): 14-16.

Patil, T. N., P. A. Saraf, R. Penukonda, S. S. Vanaki and L. Kamatagi. 2017. A survey on nickel titanium rotary instruments and their usage techniques by endodontists in India. J. Clin. Diagn. Res. 11(5): ZC29.

Ruddle, C. J. 2016. Single-file shaping technique: achieving a gold medal result. Dent Today. 35: 1-7.

Ruddle, C., P. Machtou and J. D. West. 2013. The shaping movement $5^{\text {th }}$ generation technology. Dent Today. 32(4): 94. 